\title{
Extracorporeal Membrane Oxygenation for ARDS: Optimization of Lung Protective Ventilation
}

\author{
Madhavi Parekh MD, Darryl Abrams MD, Daniel Brodie MD, and Natalie H Yip MD
}

\author{
Introduction \\ History of ECMO for ARDS \\ The ECMO Circuit and Configurations in ARDS \\ Ventilator Strategies With ECMO \\ Lung-Protective Ventilation \\ Ventilator Management With ECMO \\ Extracorporeal Carbon Dioxide Removal for Less-Severe Forms of ARDS \\ Prone Positioning During ECMO \\ Mobilization During Extracorporeal Support \\ Endotracheal Extubation During ECMO \\ Summary
}

\begin{abstract}
The use of extracorporeal membrane oxygenation in the management of ARDS has grown considerably in the past decade, largely as a consequence of improvements in extracorporeal technology and management techniques. Recently published data has helped clarify the use of ECMO in ARDS, and its role in optimizing lung-protective ventilation and minimizing ventilator-induced lung injury has the potential to have a substantial impact on ARDS management and outcomes. In the future, novel extracorporeal management strategies may lead to a new paradigm in our approach to patients with ARDS. Key words: ARDS; extracorporeal membrane oxygenation (ECMO); respiratory failure; extracorporeal life support. [Respir Care 2018;63(9):1180-1188. (C) 2018 Daedalus Enterprises]
\end{abstract}

\section{Introduction}

Extracorporeal membrane oxygenation (ECMO) was first used in the management of severe acute respiratory failure in the 1970s, but a lack of proof of clinical benefit beyond the standard of care led to a marked decline in its

\footnotetext{
Drs Parekh, Abrams, Brodie, and Yip are affiliated with the Division of Pulmonary, Allergy and Critical Care Medicine, Columbia University Medical Center, New York, New York.

Dr Brodie discloses relationships with ALung Technologies and Johnson \& Johnson. The remaining authors have disclosed no conflicts of interest.

Correspondence: Natalie Yip MD, Division of Pulmonary, Allergy \& Critical Care, Department of Medicine, 622 W 168th Street, PH 8-101E, New York, NY 10032. E-mail: nhy1@cumc.columbia.edu.
}

DOI: $10.4187 /$ respcare.06262 use. More recent advances in technology and management techniques have led to an improved risk profile and a suggestion of improved survival in patients with severe ARDS who otherwise would be expected to have a high mortality. However, the benefit of ECMO compared with conventional management for ARDS had yet to be demonstrated, until just recently, in rigorously designed, randomized controlled studies by using modern ECMO technology and strict adherence to current standard-of-care mechanical ventilation strategies. As such, ECMO technology has largely remained a rescue therapy for severe refractory ARDS. The potential advantages of ECMO over conventional management may extend beyond its role in supporting patients with refractory gas exchange impairment. The use of ECMO may facilitate and enhance the application of lung-protective ventilation by minimizing ventilator-induced lung injury beyond the current standard of care. 


\section{History of ECMO for ARDS}

The first use of ECMO as rescue therapy for severe acute respiratory failure was described in $1972,{ }^{1}$ although a subsequent randomized controlled trial failed to demonstrate a survival benefit of ECMO when compared with conventional mechanical ventilation, with high mortality rates in both groups. ${ }^{2}$ Extracorporeal carbon dioxide removal, a variation of ECMO in which the goal is the removal of carbon dioxide without the emphasis on oxygenation, was thereafter investigated as a potential modality $^{3}$ to minimize ventilator-induced lung injury by reducing the reliance on invasive mechanical ventilation by pairing extracorporeal carbon dioxide removal with verylow-frequency positive-pressure ventilation. ${ }^{4-7}$ Despite its promise, there was no benefit from this strategy over conventional management in a randomized controlled trial. ${ }^{8}$ Subsequently, several non-randomized observational studies suggested improved but variable survival rates for subjects with ARDS supported with ECMO (49-81\%).9-17 However, interpretation of these studies is limited both by their methodology and in their use of outdated extracorporeal and mechanical ventilation techniques.

Over the past couple of decades, a number of advancements in clinical management have led to improved outcomes for patients with ARDS, most notably the use of a low-volume, low-pressure ventilation strategy, conservative fluid management, neuromuscular blockade, and prone positioning. ${ }^{18-23}$ Innovations in extracorporeal technology have also occurred over this time period. ${ }^{24,25}$ The 2009 influenza A (H1N1) pandemic led to a resurgence of interest in the use of ECMO for ARDS, with higher than expected survival rates given the patients' severity of illness. ${ }^{26-32}$ However, comparable cohorts at other centers reported equally favorable outcomes without the use of ECMO. ${ }^{33}$ Subsequent matched-pairs analyses of subjects with influenza A (H1N1)-associated ARDS managed with and without ECMO also demonstrated conflicting results with regard to mortality benefit, ${ }^{34,35}$ which again calls into question the overall benefit of ECMO over optimal conventional management techniques.

Until just recently, the only multi-center randomized controlled clinical trial of ECMO for ARDS that used relatively modern technology was the CESAR (Conventional Ventilation or ECMO for Severe Adult Respiratory failure) trial, ${ }^{36}$ in which 180 subjects with potentially reversible severe, acute respiratory failure were randomized to either conventional management or referral to an ECMOcapable center where they were considered for ECMO after an initial period of standardized conventional management. Subjects referred to a specialty center had a significantly lower rate of the composite outcome of death or severe disability at 6 months compared with conventional management (37\% vs $53 \%$; relative risk $0.69,95 \%$ CI
$0.05-0.97 ; P=.03)$. However, only $70 \%$ of the subjects in the conventional arm received standard-of-care lungprotective ventilation during the study period, and only $76 \%$ of the subjects referred to the ECMO-capable center ultimately were managed with ECMO, which makes it difficult to draw conclusions with regard to the effect of ECMO itself on the management and outcomes of severe ARDS. This study does suggest that referral of patients with severe ARDS to a center capable of providing ECMO and standard-of-care lung-protective ventilation may be beneficial. 36,37 The recently completed randomized controlled trial, EOLIA (ECMO to Rescue Lung Injury in Severe ARDS), ${ }^{38}$ which compared standard-of-care management with venovenous ECMO, has helped clarify potential benefits of ECMO for patients with severe forms of ARDS. Eligible subjects, based on either severity of hypoxemia or respiratory acidosis in the context of reduced respiratory system compliance, were randomized to optimal conventional management (including standard of care lung-protective ventilation, neuromuscular blockade, and prone positioning) or ECMO combined with a ventilator strategy that mandated plateau airway pressures even lower than the current standard of care. Notably, the trial was terminated early for futility in achieving the primary endpoint (based on pre-specified stopping rules), which can be attributed, at least in part, to a high rate of crossover from control group to ECMO (28\%), along with a lower than expected mortality in the control group (46\% vs 60\%). Although the results did not meet statistical significance for the primary endpoint of mortality at day 60 (35\% in the ECMO group vs $46 \%$ in the control group; relative risk $0.76,95 \%$ CI $0.55-1.04, P=.09$ ), the overall effect estimate, along with key secondary endpoints and post-hoc analyses, suggest a benefit of ECMO over optimal conventional management, with reassuringly low rates of complications in the intervention group.

\section{The ECMO Circuit and Configurations in ARDS}

ECMO consists of an extracorporeal circuit that includes a gas-exchange device, also referred to as an oxygenator, which directly oxygenates and removes carbon dioxide from the blood across a semipermeable membrane. ECMO circuits consist of 2 primary configuration types: venovenous and venoarterial. ${ }^{39}$ Venovenous ECMO is a configuration in which deoxygenated blood is drawn from a central vein via a pump, passes through the oxygenator, and is reinfused into a central vein (Figures 1 and 2). Venovenous ECMO provides respiratory support only and is the configuration of choice in the majority of patients with severe forms of ARDS. Venoarterial ECMO, which draws deoxygenated blood from a central vein and reinfuses well-oxygenated blood into a central artery, provides both hemodynamic and respiratory support. A hybrid approach, 


\section{ECMO FOR ARDS}

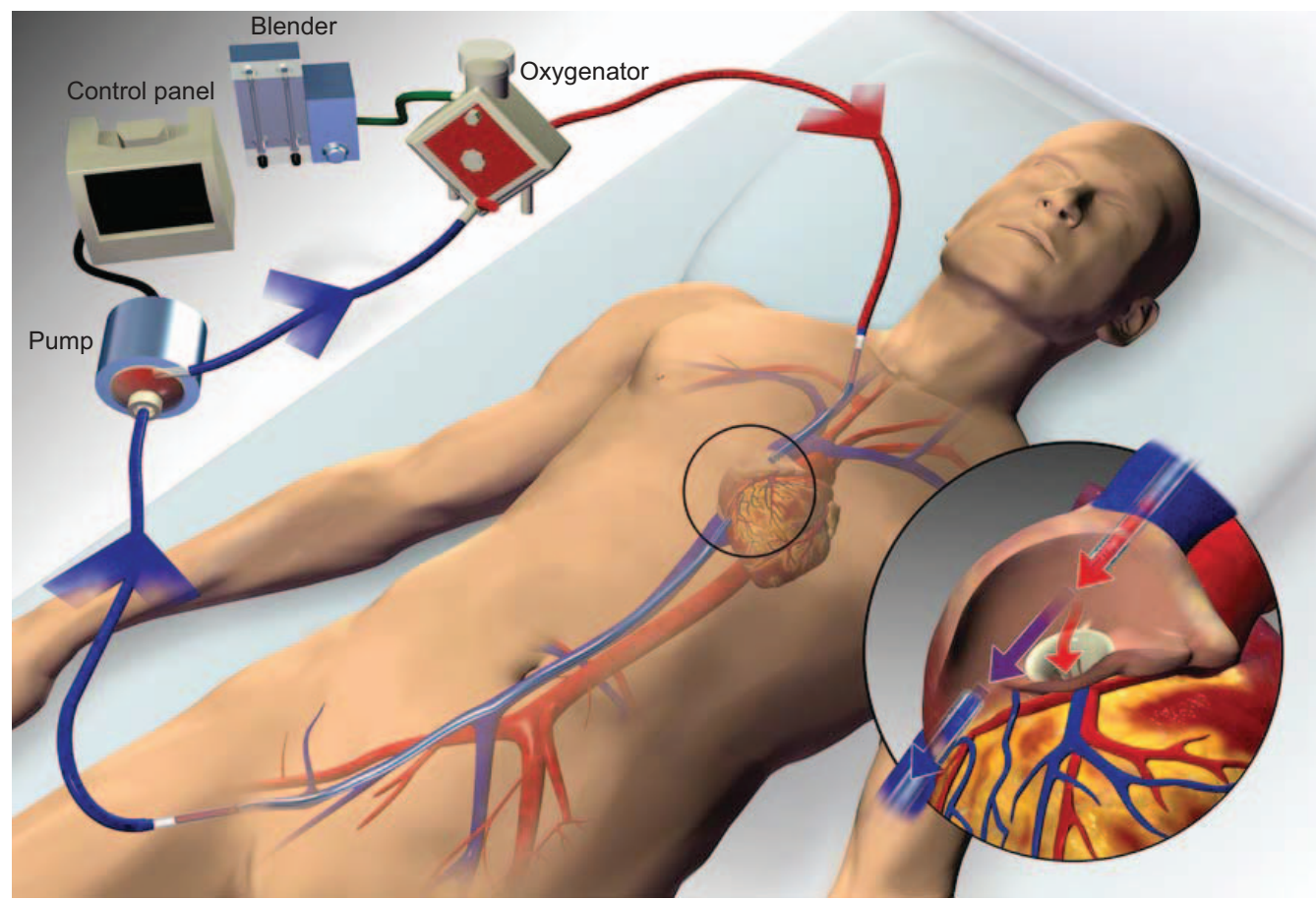

Fig. 1. Two-site approach to venovenous ECMO cannulation. The drainage cannula typically enters a femoral vein and extends into the inferior vena cava. Blood from the cannula is drawn into a pump. This blood is then propelled forward through the oxygenator before being reinfused into the body. The reinfusion cannula typically enters an internal jugular vein and extends into the right atrium, where blood is reinfused. From Reference 80, with permission.

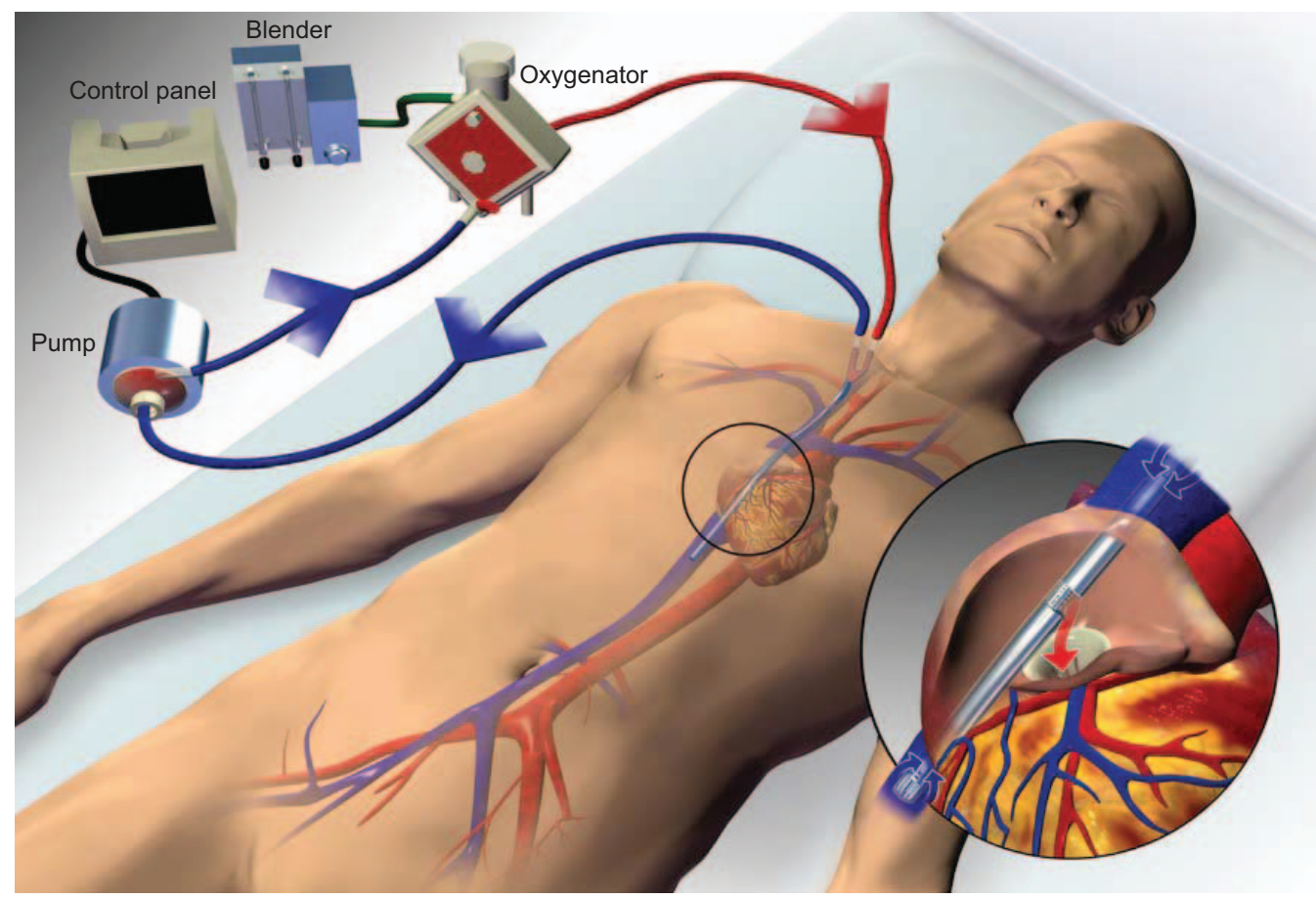

Fig. 2. Single-site approach to venovenous ECMO cannulation. A dual-lumen cannula enters the internal jugular vein and terminates in the inferior vena cava. Blood enters the drainage lumen through ports in the inferior and superior vena cava and is drawn into the pump. This blood is then propelled forward through the oxygenator before being reinfused via the second lumen of the cannula, which has a port positioned in the right atrium and blood flow is directed across the tricuspid valve. From Reference 80 , with permission. 


\section{ECMO FOR ARDS}

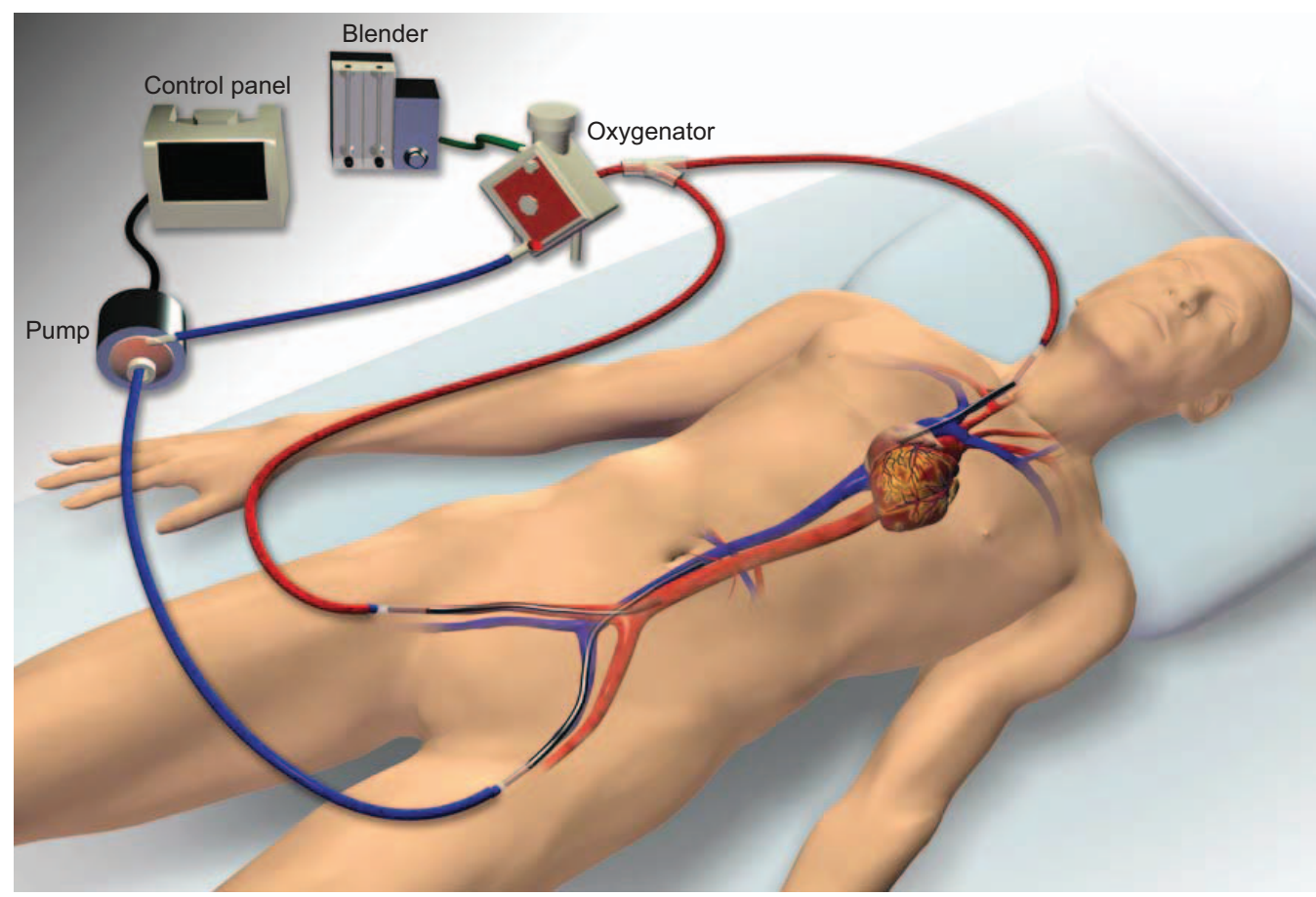

Fig. 3. Venovenous-arterial ECMO cannulation. The venous drainage cannula enters a femoral vein and extends into the inferior vena cava. This blood is then drawn into a pump and propelled forward through the oxygenator before being reinfused into the body. The reinfusion of blood is split between a venous cannula, typically placed in an internal jugular vein, and an arterial cannula, typically placed in a femoral artery. From Reference 80, with permission.

which draws deoxygenated blood from a central vein and reinfuses oxygenated blood into both a central vein and artery, referred to as venovenous-arterial ECMO (Figure 3), may be beneficial for patients with ARDS and concomitant severe cardiogenic shock to provide both hemodynamic support and adequate upper body oxygenation. ${ }^{39-42}$

Cannulation approaches for venovenous ECMO may be performed with either dual- or single-site techniques. The dual-site approach draws blood, for instance, from a femoral vein and reinfuses blood into either an internal jugular or contralateral femoral vein (Figure 1). Alternatively, a single-site approach, which involves placement of a bicaval dual-lumen cannula, typically into an internal jugular or femoral vein, permits both drainage and reinfusion through a single vascular access point (Figure 2). Although this approach often requires either fluoroscopic or transesophageal echocardiographic guidance for placement, it may avoid femoral cannulation, which can help optimize mobilization in select patients. ${ }^{39,43,44}$

\section{Ventilator Strategies With ECMO}

\section{Lung-Protective Ventilation}

ECMO may be considered a salvage therapy for patients with severe, refractory ARDS (Figure 4). The essence of
ECMO support in these cases is 2-fold: first, to ensure adequate oxygenation and ventilation, and, second, to minimize ventilator-induced lung injury by facilitating at least standard-of-care, low-volume, low-pressure ventilation, which may otherwise be difficult to achieve with conventional management alone. ${ }^{39}$ Although a lung-protective strategy is the hallmark of ventilator management in ARDS, ${ }^{19,45-48}$ the optimal targets for such a strategy remain unknown. Secondary analysis of the ARDS Network Low Tidal Volume Trial ${ }^{19}$ found that the subjects with the lowest end-inspiratory plateau airway pressures on day 1 had lower mortality than those with higher plateau airway pressures, which indicates that a lower target may be more protective. ${ }^{48,49}$ However, the ability to achieve these lower-than-standard plateau airway pressures in patients with severe forms of ARDS and with severely reduced lung compliance is often limited by prohibitive respiratory acidosis that results from the reduction in minute ventilation. ECMO can manage the hypercapnia and respiratory acidosis that accompany reductions in tidal volumes and plateau airway pressures by directly removing carbon dioxide from the blood. However, it is unknown if such a strategy of ECMO-facilitated very-low tidal volume ventilation is superior to conventional low tidal volume ventilation or other rigorously studied adjunctive therapies, for example, prone positioning. ${ }^{19,23}$ 


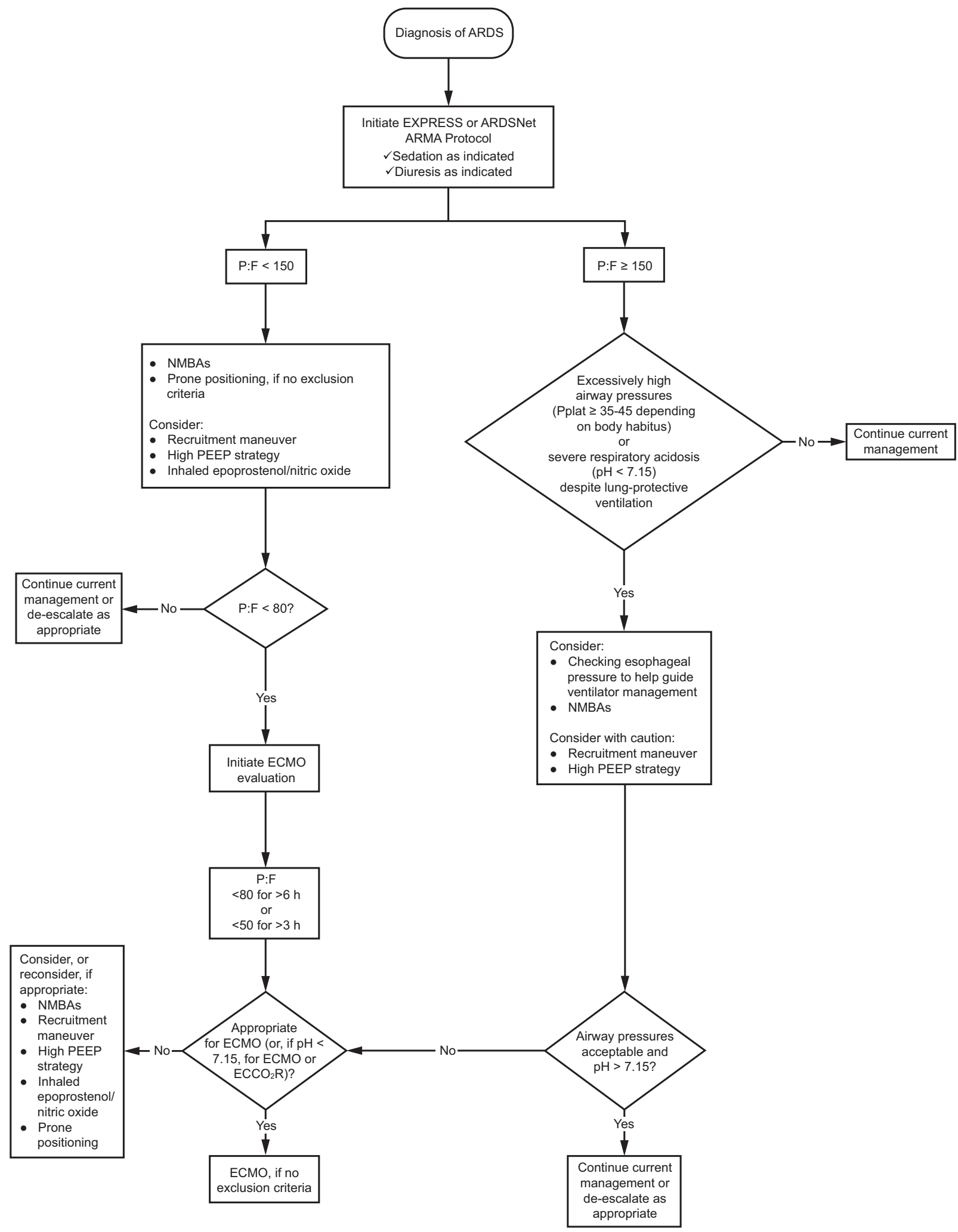

Fig. 4. Management algorithm for patients with ARDS. Initial management for patients diagnosed with ARDS should include a low-volume, low-pressure ventilation strategy, with sedation and diuresis, as appropriate. Further interventions should be considered based on the severity of the ARDS. ECMO = extracorporeal membrane oxygenation. From Reference 81, with permission. 


\section{Ventilator Management With ECMO}

The CESAR trial ${ }^{50}$ managed subjects who received ECMO with pressure-controlled ventilation with a target peak inspiratory pressure of $20-25 \mathrm{~cm} \mathrm{H}_{2} \mathrm{O}$, a frequency of 10 breaths/min, PEEP of $10-15 \mathrm{~cm} \mathrm{H}_{2} \mathrm{O}$, and a $\mathrm{F}_{\mathrm{IO}_{2}}$ of 0.3 . This ventilator management strategy, or one that aims to optimize lung protection, has often been adopted by ECMO centers, although current practices vary widely. ${ }^{51,52}$ It is unknown if these settings are optimal because this strategy has not been directly compared with any other ventilator strategy during ECMO, including volume-controlled modes with or without particular airway pressure targets. As mentioned, the optimal target plateau airway pressure is unknown, and analysis of prospective data indicates that targeting even lower volumes and pressures may be beneficial. ${ }^{48}$ Given the findings of the EOLIA trial, which used a plateau airway pressure limit of $24 \mathrm{~cm} \mathrm{H} \mathrm{H}_{2} \mathrm{O}$, PEEP of at least $10 \mathrm{~cm} \mathrm{H}_{2} \mathrm{O}, \mathrm{F}_{\mathrm{IO}_{2}}$ of $0.3-0.5$, and a breathing frequency of 10-30 breaths per minute in the ECMO group, it would be reasonable to consider these parameters as the new standard in ventilator management for patients receiving ECMO support. ${ }^{38}$

Analysis of combined data from large-volume ECMO centers also indicates that higher PEEP during the first few days of ECMO support for ARDS is associated with reduced mortality (odds ratio 0.75 , 95\% CI $0.64-0.88$; $P<.001) .{ }^{53}$ In addition, there are data that the breathing frequency may also be a significant contributor to ventilator-induced lung injury and that targeting lower respiratory rates may be beneficial. ${ }^{54,55}$ Analysis of pooled data of patients managed with mechanical ventilation with or without venovenous ECMO indicates that driving pressure (end-inspiratory plateau airway pressure minus PEEP) is independently associated with mortality (adjusted hazard ratio $1.06,95 \%$ CI $1.03-1.10 ; P<.001$ ) and that perhaps targeting a lower driving pressure would improve outcomes. ${ }^{56,57}$ However, the strategy of reducing driving pressure has not been well studied in a prospective, randomized fashion, which limits its adoption for the time being. Furthermore, a recent randomized controlled trial of recruitment maneuvers and titrated PEEP strategies demonstrated an increased mortality despite reductions in driving pressure, which called into question the performance of driving pressure as a suitable biomarker in ventilatory management in ARDS. 58

\section{Extracorporeal Carbon Dioxide Removal for Less-Severe Forms of ARDS}

Although ECMO has largely been reserved as a salvage therapy for patients with severe, refractory ARDS, there is increasing interest in the use of extracorporeal carbon di- oxide removal, which can be achieved with lower blood flows, smaller cannulae, and a potentially more favorable risk/benefit profile, to facilitate or extend lung-protective ventilation. Because the lower blood flows of extracorporeal carbon dioxide removal do not significantly contribute to oxygenation, this approach may be best suited for lesssevere forms of ARDS. The concept of extracorporeal carbon dioxide removal assisted very-low tidal volume ventilation in patients with ARDS was studied in a prospective trial that reduced tidal volumes from $6 \mathrm{~mL} / \mathrm{kg}$ of predicted body weight to $4 \mathrm{~mL} / \mathrm{kg}$, with a goal reduction in plateau pressure from $28-30 \mathrm{~cm} \mathrm{H}_{2} \mathrm{O}$ to $25-27 \mathrm{~cm} \mathrm{H}_{2} \mathrm{O}$. Inflammatory markers, interleukin-6, interleukin-8, interleukin-1b, and interleukin-1 receptor antagonist, were reduced, which indicated a biologic mitigation of ventilatorassociated injury. ${ }^{59}$ Thereafter, a randomized controlled trial that compared extracorporeal carbon dioxide removal assisted very-low tidal volume ventilation $(3 \mathrm{~mL} / \mathrm{kg}$ predicted body weight) with standard low-tidal volume ventilation in subjects with moderate ARDS did not demonstrate a difference in the primary outcome of ventilatorfree days between groups but did indicate a reduction in ventilator-free days among subjects with more-severe hypoxemia. ${ }^{60}$ Although analysis of data that supports the use of extracorporeal carbon dioxide removal for facilitation of very-low tidal volume ventilation in a wider range of patients with ARDS are currently limited, extracorporeal carbon dioxide removal remains an area of active investigation. ${ }^{61,62}$

\section{Prone Positioning During ECMO}

The significant improvement in mortality achieved with prone positioning when combined with low-volume, lowpressure ventilation ${ }^{23}$ makes this a foundational strategy for patients with moderate-to-severe forms of ARDS in centers where there is experience with the technique and should be performed, whenever possible, before consideration of ECMO. Prone positioning may have a benefit when combined with ECMO, with case series that indicate it is safe and feasible. ${ }^{63}$ However, more data are needed before such an approach can be recommended.

\section{Mobilization During Extracorporeal Support}

Active physical and occupational therapies have been shown to be both feasible and favorable for patients with acute respiratory failure by improving delirium and functionality, and increasing ventilator-free days. ${ }^{64-66}$ Mobilization of patients with respiratory failure who require ECMO has largely been limited to patients with chronic respiratory failure awaiting lung transplantation ${ }^{67-70}$ but may also be appropriate in select patients with ARDS. ${ }^{71-73}$ However, little is known about the efficacy or safety in 
patients with ARDS who receive ECMO. Any attempt at active physical therapy in these patients would ideally be performed at centers with a carefully designed, multidisciplinary approach to ensure safety.

\section{Endotracheal Extubation During ECMO}

As previously stated, a fundamental goal of mechanical ventilation strategies during ECMO is to minimize ventilator-induced lung injury, a major contributor to morbidity and mortality in ARDS. ${ }^{19}$ As such, endotracheal extubation and liberation from invasive mechanical ventilation, when ECMO support is sufficient to manage oxygenation and ventilation, could be an optimal strategy. Additional ventilatory support could also be provided by noninvasive means in addition to ECMO, namely noninvasive positivepressure ventilation or high-flow nasal cannula, in an attempt to facilitate extubation. Extubation could also potentially minimize additional complications associated with ventilator dependence, including the need for sedation, ventilator-associated pneumonia, critical-illness-related weakness due to immobilization, ${ }^{71-74}$ and malnutrition. However, spontaneous breathing may exacerbate lung injury by increasing mechanical stress, which may be difficult to predict or control. ${ }^{75-78}$ Although extracorporeal carbon dioxide removal has been shown to aid in controlling ventilatory drive in patients with chronic respiratory failure, it may not be sufficient in reducing the potential injurious effects of spontaneous breathing in patients with severe ARDS. ${ }^{64,76,79}$ More data are needed to determine in whom such a strategy might be considered and whether this approach is superior to optimal invasive mechanical ventilation.

\section{Summary}

Minimizing ventilator-associated lung injury is the hallmark of current management strategies for patients with ARDS. The concurrent use of ECMO facilitates lung-protective ventilation in patients with severe ARDS and may create the opportunity to achieve lung-protective ventilation beyond the current standard of care. Emerging data from a recent randomized controlled trial have helped to clarify the role of ECMO in ARDS, though much remains to be determined about the optimal ventilator management for patients receiving ECMO support.

\section{REFERENCES}

1. Hill JD, O’Brien TG, Murray JJ, Dontigny L, Bramson ML, Osborn JJ, Gerbode F. Prolonged extracorporeal oxygenation for acute posttraumatic respiratory failure (shock-lung syndrome). Use of the Bramson membrane lung. N Engl J Med 1972;286(12):629-634.

2. Zapol WM, Snider MT, Hill JD, Fallat RJ, Bartlett RH, Edmunds $\mathrm{LH}$, et al. Extracorporeal membrane oxygenation in severe acute respiratory failure. A randomized prospective study. JAMA 1979; 242(20):2193-2196.

3. Sherlock JE, Yoon Y, Ledwith JW, Letteri JM. Respiratory gas exchange during hemodialysis. Proc Clin Dial Transplant Forum 1972;2:171-174.

4. Gattinoni L, Kolobow T, Damia G, Agostoni A, Pesenti A. Extracorporeal carbon dioxide removal (ECCO2R): a new form of respiratory assistance. Int J Artif Organs 1979;2(4):183-185.

5. Gattinoni L, Agostoni A, Pesenti A, Pelizzola A, Rossi GP, Langer $\mathrm{M}$, et al. Treatment of acute respiratory failure with low-frequency positive-pressure ventilation and extracorporeal removal of $\mathrm{CO} 2$. Lancet 1980;2(8189):292-294.

6. Gattinoni L, Pesenti A, Caspani ML, Pelizzola A, Mascheroni D, Marcolin R, et al. The role of total static lung compliance in the management of severe ARDS unresponsive to conventional treatment. Intensive Care Med 1984;10(3):121-126.

7. Gattinoni L, Pesenti A, Mascheroni D, Marcolin R, Fumagalli R, Rossi F, et al. Low-frequency positive-pressure ventilation with extracorporeal $\mathrm{CO} 2$ removal in severe acute respiratory failure. JAMA 1986;256(7):881-886.

8. Morris AH, Wallace CJ, Menlove RL, Clemmer TP, Orme JF Jr, Weaver LK, et al. Randomized clinical trial of pressure-controlled inverse ratio ventilation and extracorporeal $\mathrm{CO} 2$ removal for adult respiratory distress syndrome. Am J Respir Crit Care Med 1994; 149(2 Pt 1):295-305.

9. Wagner PK, Knoch M, Sangmeister C, Müller E, Lennartz H, Rothmund M. Extracorporeal gas exchange in adult respiratory distress syndrome: associated morbidity and its surgical treatment. Br J Surg 1990;77(12):1395-1398.

10. Brunet F, Belghith M, Mira JP, Lanore JJ, Vaxelaire JF, Dall'ava Santucci J, Dhainaut JF. Extracorporeal carbon dioxide removal and low-frequency positive-pressure ventilation. Improvement in arterial oxygenation with reduction of risk of pulmonary barotrauma in patients with adult respiratory distress syndrome. Chest 1993;104(3): 889-898.

11. Kolla S, Awad SS, Rich PB, Schreiner RJ, Hirschl RB, Bartlett RH. Extracorporeal life support for 100 adult patients with severe respiratory failure. Ann Surg 226(4):544-564, 1997; discussion 565-546.

12. Lewandowski K, Rossaint R, Pappert D, Gerlach H, Slama KJ, Weidemann $\mathrm{H}$, et al. High survival rate in 122 ARDS patients managed according to a clinical algorithm including extracorporeal membrane oxygenation. Intensive Care Med 1997;23(8):819-835.

13. Manert W, Haller M, Briegel J, Hummel T, Kilger E, Polasek J, et al. [Venovenous extracorporeal membrane oxygenation (ECMO) with a heparin-lock bypass system. An effective addition in the treatment of acute respiratory failure (ARDS)] Anaesthesist 1996; 45(5):437-448.

14. Peek GJ, Moore HM, Moore N, Sosnowski AW, Firmin RK. Extracorporeal membrane oxygenation for adult respiratory failure. Chest 1997;112(3):759-764.

15. Bartlett RH, Roloff DW, Custer JR, Younger JG, Hirschl RB. Extracorporeal life support: the University of Michigan experience. JAMA 2000;283(7):904-908.

16. Lindén V, Palmér K, Reinhard J, Westman R, Ehrén H, Granholm T, Frenckner B. High survival in adult patients with acute respiratory distress syndrome treated by extracorporeal membrane oxygenation, minimal sedation, and pressure supported ventilation. Intensive Care Med 2000;26(11):1630-1637.

17. Schmid C, Philipp A, Hilker M, Rupprecht L, Arlt M, Keyser A, et al. Venovenous extracorporeal membrane oxygenation for acute lung failure in adults. J Heart Lung Transplant 2012;31(1):9-15.

18. Amato MB, Barbas CS, Medeiros DM, Magaldi RB, Schettino GP, Lorenzi-Filho G, et al. Effect of a protective-ventilation strategy on 
mortality in the acute respiratory distress syndrome. N Engl J Med 1998;338(6):347-354.

19. Acute Respiratory Distress Syndrome Network, Brower RG, Matthay MA, Morris A, Schoenfeld D, Thompson BT, Wheeler A. Ventilation with lower tidal volumes as compared with traditional tidal volumes for acute lung injury and the acute respiratory distress syndrome. N Engl J Med 2000;342(18):1301-1308.

20. Villar J, Kacmarek RM, Pérez-Méndez L, Aguirre-Jaime A. A high positive end-expiratory pressure, low tidal volume ventilatory strategy improves outcome in persistent acute respiratory distress syndrome: a randomized, controlled trial. Crit Care Med 2006;34(5): 1311-1318.

21. National Heart, Lung, and Blood Institute Acute Respiratory Distress Syndrome (ARDS) Clinical Trials Network, Wiedemann HP, Wheeler AP, Bernard GR, Thompson BT, Hayden D, deBoisblanc B, et al. Comparison of two fluid-management strategies in acute lung injury. N Engl J Med 2006;354(24):2564-2575.

22. Papazian L, Forel JM, Gacouin A, Penot-Ragon C, Perrin G, Loundou A, et al; ACURASYS Study Investigators. Neuromuscular blockers in early acute respiratory distress syndrome. N Engl J Med 2010; 363(12):1107-1116.

23. Guérin C, Reignier J, Richard JC, Beuret P, Gacouin A, Boulain T, et al; PROSEVA Study Group. Prone positioning in severe acute respiratory distress syndrome. N Engl J Med 2013;368(23):21592168.

24. Wang D, Zhou X, Liu X, Sidor B, Lynch J, Zwischenberger JB. Wang-Zwische double lumen cannula-toward a percutaneous and ambulatory paracorporeal artificial lung. ASAIO J 2008;54(6):606611.

25. Bottrell S, Bennett M, Augustin S, Thuys C, Schultz B, Horton A, et al. A comparison study of haemolysis production in three contemporary centrifugal pumps. Perfusion 2014;29(5):411-416.

26. Australia and New Zealand Extracorporeal Membrane Oxygenation (ANZ ECMO) Influenza Investigators, Davies A, Jones D, Bailey M, Beca J, Bellomo R, Blackwell N, et al. Extracorporeal Membrane Oxygenation for 2009 Influenza A(H1N1) Acute Respiratory Distress Syndrome. JAMA 2009;302(17):1888-1895.

27. Davies A, Jones D, Gattas D. Extracorporeal Membrane Oxygenation for ARDS Due to 2009 Influenza A(H1N1)—Reply. JAMA 2010;303(10):941-942.

28. Holzgraefe B, Broomé M, Kalzén H, Konrad D, Palmér K, Frenckner B. Extracorporeal membrane oxygenation for pandemic H1N1 2009 respiratory failure. Minerva Anestesiol 2010;76(12):1043-1051.

29. Roch A, Lepaul-Ercole R, Grisoli D, Bessereau J, Brissy O, Castanier $\mathrm{M}$, et al. Extracorporeal membrane oxygenation for severe influenza A (H1N1) acute respiratory distress syndrome: a prospective observational comparative study. Intensive Care Med 2010;36(11): 1899-1905.

30. Patroniti N, Zangrillo A, Pappalardo F, Peris A, Cianchi G, Braschi A, et al. The Italian ECMO network experience during the 2009 influenza $\mathrm{A}(\mathrm{H} 1 \mathrm{~N} 1)$ pandemic: preparation for severe respiratory emergency outbreaks. Intensive Care Med 2011;37(9):1447-1457.

31. Karagiannidis C, Brodie D, Strassmann S, Stoelben E, Philipp A, Bein T, et al. Extracorporeal membrane oxygenation: evolving epidemiology and mortality. Intensive Care Med 2016;42(5):889-896.

32. Thiagarajan RR, Barbaro RP, Rycus PT, McMullan DM, Conrad SA, Fortenberry JD, et al. Extracorporeal Life Support Organization Registry International Report 2016. ASAIO Journal 2017;63(1):60-67.

33. Miller RR III, Markewitz BA, Rolfs RT, Brown SM, Dascomb KK, Grissom CK, et al. Clinical findings and demographic factors associated with ICU admission in Utah due to novel 2009 influenza A(H1N1) infection. Chest 2010;137(4):752-758.

34. Noah MA, Peek GJ, Finney SJ, Griffiths MJ, Harrison DA, Grieve $\mathrm{R}$, et al. Referral to an extracorporeal membrane oxygenation center and mortality among patients with severe 2009 influenza A(H1N1). JAMA 2011;306(15):1659-1668.

35. Pham T, Combes A, Rozé H, Chevret S, Mercat A, Roch A, et al; REVA Research Network. Extracorporeal Membrane Oxygenation for Pandemic Influenza A(H1N1)-induced Acute Respiratory Distress Syndrome: A Cohort Study and Propensity-matched Analysis. Am J Respir Crit Care Med 2013;187(3):276-285.

36. Peek GJ, Mugford M, Tiruvoipati R, Wilson A, Allen E, Thalanany $\mathrm{MM}$, et al; CESAR trial collaboration. Efficacy and economic assessment of conventional ventilatory support versus extracorporeal membrane oxygenation for severe adult respiratory failure (CESAR): a multicentre randomised controlled trial. Lancet 2009;374(9698): 1351-1363.

37. Zwischenberger JB, Lynch JE. Will CESAR answer the adult ECMO debate? Lancet 2009;374(9698):1307-1308.

38. Combes A, Hajage D, Capellier G, Demoule A, Lavoue S, Guervilly C, et al. Extracorporeal Membrane Oxygenation for Severe Acute Respiratory Distress Syndrome. N Engl J Med 2018;378(21): 1965-1975.

39. Brodie D, Bacchetta M. Extracorporeal membrane oxygenation for ARDS in adults. N Engl J Med 2011;365(20):1905-1914.

40. Biscotti M, Lee A, Basner RC, Agerstrand C, Abrams D, Brodie D, Bacchetta M. Hybrid configurations via percutaneous access for extracorporeal membrane oxygenation: a single-center experience. ASAIO J 2014;60(6):635-642.

41. Bréchot N, Luyt CE, Schmidt M, Leprince P, Trouillet JL, Léger P, et al. Venoarterial extracorporeal membrane oxygenation support for refractory cardiovascular dysfunction during severe bacterial septic shock. Crit Care Med 2013;41(7):1616-1626.

42. Abrams D, Brodie D. Emerging indications for extracorporeal membrane oxygenation in adults with respiratory failure. Ann Am Thoracic Soc 2013;10(4):371-377.

43. Javidfar J, Wang D, Zwischenberger JB, Costa J, Mongero L, Sonett J, Bacchetta M. Insertion of bicaval dual lumen extracorporeal membrane oxygenation catheter with image guidance. ASAIO J 2011; 57(3):203-205.

44. Javidfar J, Brodie D, Wang D, Ibrahimiye AN, Yang J, Zwischenberger JB, et al. Use of bicaval dual-lumen catheter for adult venovenous extracorporeal membrane oxygenation. Ann Thorac Surg 2011;91(6):1763-1768; discussion 1769.

45. Parsons PE, Eisner MD, Thompson BT, Matthay MA, Ancukiewicz M, Bernard GR, Wheeler AP; NHLBI Acute Respiratory Distress Syndrome Clinical Trials Network. Lower tidal volume ventilation and plasma cytokine markers of inflammation in patients with acute lung injury. Crit Care Med 33(1):1-6, 2005; discussion 230-232.

46. Ranieri VM, Suter PM, Tortorella C, De Tullio R, Dayer JM, Brienza A, et al. Effect of mechanical ventilation on inflammatory mediators in patients with acute respiratory distress syndrome: a randomized controlled trial. JAMA 1999;282(1):54-61.

47. Putensen C, Theuerkauf N, Zinserling J, Wrigge H, Pelosi P. Metaanalysis: ventilation strategies and outcomes of the acute respiratory distress syndrome and acute lung injury. Ann Intern Med 2009; 151(8):566-576.

48. Needham DM, Colantuoni E, Mendez-Tellez PA, Dinglas VD, Sevransky JE, Dennison Himmelfarb CR, et al. Lung protective mechanical ventilation and two year survival in patients with acute lung injury: prospective cohort study. BMJ 2012;344:e2124.

49. Hager DN, Krishnan JA, Hayden DL, Brower RG. Tidal volume reduction in patients with acute lung injury when plateau pressures are not high. Am J Respir Crit Care Med 2005;172(10):1241-1245.

50. Peek GJ, Elbourne D, Mugford M, Tiruvoipati R, Wilson A, Allen E, et al. Randomised controlled trial and parallel economic evaluation of conventional ventilatory support versus extracorporeal membrane 
oxygenation for severe adult respiratory failure (CESAR). Health Technol Assess 2010;14(35):1-46.

51. Marhong JD, Telesnicki T, Munshi L, Del Sorbo L, Detsky M, Fan E. Mechanical ventilation during extracorporeal membrane oxygenation. An international survey. Ann Am Thorac Soc 2014;11(6):956961.

52. Marhong JD, Munshi L, Detsky M, Telesnicki T, Fan E. Mechanical ventilation during extracorporeal life support (ECLS): a systematic review. Intensive Care Med 2015;41(6):994-1003.

53. Schmidt M, Stewart C, Bailey M, Nieszkowska A, Kelly J, Murphy $\mathrm{L}$, et al. Mechanical ventilation management during extracorporeal membrane oxygenation for acute respiratory distress syndrome: a retrospective international multicenter study. Crit Care Med 2015; 43(3):654-664.

54. Gattinoni L, Tonetti T, Cressoni M, Cadringher P, Herrmann P, Moerer $\mathrm{O}$, et al. Ventilator-related causes of lung injury: the mechanical power. Intensive Care Med 2016;42(10):1567-1575.

55. Grasso S, Stripoli T, Mazzone P, Pezzuto M, Lacitignola L, Centonze $\mathrm{P}$, et al. Low respiratory rate plus minimally invasive extracorporeal $\mathrm{CO} 2$ removal decreases systemic and pulmonary inflammatory mediators in experimental Acute Respiratory Distress Syndrome. Crit Care Med 2014;42(6):e451-e460.

56. Amato MB, Meade MO, Slutsky AS, Brochard L, Costa EL, Schoenfeld DA, et al. Driving Pressure and Survival in the Acute Respiratory Distress Syndrome. N Engl J Med 2015;372(8):747-755.

57. Serpa Neto A, Schmidt M, Azevedo LC, Bein T, Brochard L, Beutel G, et al; ReVA Research Network and the PROVE Network Investigators. Associations between ventilator settings during extracorporeal membrane oxygenation for refractory hypoxemia and outcome in patients with acute respiratory distress syndrome: a pooled individual patient data analysis. Intensive Care Med 2016;42(11):16721684.

58. Writing Group for the Alveolar Recruitment for Acute Respiratory Distress Syndrome Trial (ART) Investigators, Cavalcanti AB, Suzumura ÉA, Laranjeira LN, Paisani DM, Damiani LP, Guimarães HP, et al. Effect of Lung Recruitment and Titrated Positive End-Expiratory Pressure (PEEP) vs Low PEEP on Mortality in Patients With Acute Respiratory Distress Syndrome: A Randomized Clinical Trial. JAMA 2017;318(14):1335-1345.

59. Terragni PP, Del Sorbo L, Mascia L, Urbino R, Martin EL, Birocco A, et al. Tidal volume lower than $6 \mathrm{ml} / \mathrm{kg}$ enhances lung protection: role of extracorporeal carbon dioxide removal. Anesthesiology 2009; 111(4):826-835

60. Bein T, Weber-Carstens S, Goldmann A, Müller T, Staudinger T, Brederlau J, et al. Lower tidal volume strategy $(\approx 3 \mathrm{ml} / \mathrm{kg})$ combined with extracorporeal $\mathrm{CO} 2$ removal versus 'conventional' protective ventilation $(6 \mathrm{ml} / \mathrm{kg})$ in severe ARDS : The prospective randomized Xtravent-study. Intensive Care Med 2013;39(5):847-856.

61. McNamee JJ, Gillies MA, Barrett NA, Agus AM, Beale R, Bentley $\mathrm{A}$, et al. pRotective vEntilation with veno-venouS lung assisT in respiratory failure: A protocol for a multicentre randomised controlled trial of extracorporeal carbon dioxide removal in patients with acute hypoxaemic respiratory failure. J Intensive Care Soc 2017; 18(2):159-169.

62. Fanelli V, Ranieri MV, Mancebo J, Moerer O, Quintel M, Morley S, et al. Feasibility and safety of low-flow extracorporeal carbon dioxide removal to facilitate ultra-protective ventilation in patients with moderate acute respiratory distress sindrome. Crit Care 2016;20:36.

63. Guervilly C, Hraiech S, Gariboldi V, Xeridat F, Dizier S, Toesca R, et al. Prone positioning during veno-venous extracorporeal membrane oxygenation for severe acute respiratory distress syndrome in adults. Minerva Anestesiol 2014;80(3):307-313.

64. Schweickert WD, Pohlman MC, Pohlman AS, Nigos C, Pawlik AJ, Esbrook CL, et al. Early physical and occupational therapy in me- chanically ventilated, critically ill patients: a randomised controlled trial. Lancet 2009;373(9678):1874-1882.

65. Needham DM, Korupolu R. Rehabilitation quality improvement in an intensive care unit setting: implementation of a quality improvement model. Top Stroke Rehabil 2010;17(4):271-281.

66. Bailey P, Thomsen GE, Spuhler VJ, Blair R, Jewkes J, Bezdjian L, et al. Early activity is feasible and safe in respiratory failure patients. Crit Care Med 2007;35(1):139-145.

67. Turner DA, Cheifetz IM, Rehder KJ, Williford WL, Bonadonna D, Banuelos SJ, et al. Active rehabilitation and physical therapy during extracorporeal membrane oxygenation while awaiting lung transplantation: a practical approach. Crit Care Med 2011;39(12):2593-2598.

68. Rehder KJ, Turner DA, Hartwig MG, Williford WL, Bonadonna D, Walczak RJ Jr, et al. Active rehabilitation during extracorporeal membrane oxygenation as a bridge to lung transplantation. Respir Care 2013; 58(8):1291-1298.

69. Javidfar J, Brodie D, Iribarne A, Jurado J, Lavelle M, Brenner K, et al. Extracorporeal membrane oxygenation as a bridge to lung transplantation and recovery. J Thorac Cardiovasc Surg 2012;144(3): 716-721.

70. Abrams DC, Brenner K, Burkart KM, Agerstrand CL, Thomashow BM, Bacchetta M, Brodie D. Pilot study of extracorporeal carbon dioxide removal to facilitate extubation and ambulation in exacerbations of chronic obstructive pulmonary disease. Ann Am Thorac Soc 2013;10(4):307-314.

71. Abrams D, Javidfar J, Farrand E, Mongero LB, Agerstrand CL, Ryan P, et al. Early mobilization of patients receiving extracorporeal membrane oxygenation: a retrospective cohort study. Crit Care 2014;18(1):R38.

72. Munshi L, Kobayashi T, DeBacker J, Doobay R, Telesnicki T, Lo V, et al. Intensive Care Physiotherapy during Extracorporeal Membrane Oxygenation for Acute Respiratory Distress Syndrome. Ann Am Thorac Soc 2017;14(2):246-253.

73. Ko Y, Cho YH, Park YH, Lee H, Suh GY, Yang JH, et al. Feasibility and Safety of Early Physical Therapy and Active Mobilization for Patients on Extracorporeal Membrane Oxygenation. ASAIO J 2015; 61(5):564-568.

74. Wahab R, Yip NH, Chandra S, Nguyen M, Pavlovich KH, Benson T, et al. The implementation of an early rehabilitation program is associated with reduced length of stay: A multi-ICU study. J Intensive Care Soc 2016;17(1):2-11.

75. Yoshida T, Torsani V, Gomes S, De Santis RR, Beraldo MA, Costa EL, et al. Spontaneous effort causes occult pendelluft during mechanical ventilation. Am J Respir Crit Care Med 2013;188(12):1420-1427.

76. Brochard L, Slutsky A, Pesenti A. Mechanical Ventilation to Minimize Progression of Lung Injury in Acute Respiratory Failure. Am J Respir Crit Care Med 2017;195(4):438-442.

77. Nosotti M, Rosso L, Tosi D, Palleschi A, Mendogni P, Nataloni IF, et al. Extracorporeal membrane oxygenation with spontaneous breathing as a bridge to lung transplantation. Interact Cardiovasc Thorac Surg 2013;16(1):55-59.

78. Mauri T, Bellani G, Grasselli G, Confalonieri A, Rona R, Patroniti $\mathrm{N}$, Pesenti A. Patient-ventilator interaction in ARDS patients with extremely low compliance undergoing ECMO: a novel approach based on diaphragm electrical activity. Intensive Care Med 2013; 39(2):282-291

79. Crotti S, Bottino N, Ruggeri GM, Spinelli E, Tubiolo D, Lissoni A, et al. Spontaneous Breathing during Extracorporeal Membrane Oxygenation in Acute Respiratory Failure. Anesthesiology 2017;126(4): 678-687.

80. Agerstrand CL, Bacchetta MD, Brodie D. ECMO for adult respiratory failure: current use and evolving applications. ASAIO J 2014; 60(3):255-262.

81. Brodie D, Guérin C. Rescue therapy for refractory ARDS should be offered early: no. Intensive Care Med 2015;41(5):926-929. 